\title{
Sacral Region Massage as an Alternative to the Urinary Catheter Used to Prevent Urinary Retention after Cesarean Delivery
}

\author{
Ümran Dal', Aslı Er Korucu', Kafiye Eroğlu², Belkıs Karataş', Ali Yalçın ${ }^{3}$ \\ ${ }^{1}$ Department of Nursing, Faculty of Health Science, Near East University, Nicosia, Turkish Republic of Northern Cyprus \\ ${ }^{2}$ Department of Nursing, Faculty of Health Science, Hacettepe University, Ankara, Turkey \\ ${ }^{3}$ Department of Gynecology and Obstetrics, Life Hospital, Gazi Mağusa, Turkish Republic of Northern Cyprus
}

\begin{abstract}
Objective: The aim of the study was to determine the effect of massage to the sacral region after cesarean delivery instead of employing a urinary catheter for the prevention of urinary retention.

Study Design: Cross sectional study.

Material and Methods: This interventional study population consisted of 60 women who were divided into two intervention groups and one control group. For the first intervention group, the sacral region was massaged every hour 10-15 minutes after cesarean delivery and every 30 minutes after a voiding sensation for the second intervention group. No interventions were made in the control group, although routine hospital services were provided. Socio-demographic data were collected using a questionnaire developed by the researchers. Other data were collected via observation.

Results: Fifteen percent (15\%) of the women in the first intervention group needed to void 2 hours after cesarean delivery, $35 \%$ after 3 hours, and the mean time to void after delivery was $3.4 \pm 0.8$ hours. Forty percent (40\%) of the women in the second intervention group needed to void after 5 hours, and the mean time to void after delivery was $5.5 \pm 0.8$ hours. Sixty percent $(60 \%)$ of the women in the control group needed to void 6 hours later, and the mean time to void after delivery was $6.2 \pm 0.7$ hours. Urinary retention was not observed in the first intervention group. Our statistical analysis showed a significant difference between the three groups in terms of mean times to void after cesarean delivery $(p<0.05)$.
\end{abstract}

Conclusion: In order to facilitate voiding and to prevent urinary retention, which is seen as a post-cesarean complication, massaging the sacral region could be recommended instead of urinary catheter insertion. Additional studies with larger groups are also recommended.

Key Words: Cesarean, urinary retention, urinary catheter, massage, postoperative complications, postoperative care, nurse

\section{Introduction}

Urinary retention is failure to void in the postoperative period even though the urinary bladder is full. Urinary retention, which can be seen in the early postoperative period (the first 6-8 hours), is a general complication that can also be seen in patients who do not have known urinary complaints. Many factors play a role in the development of postoperative urinary retention. Although age is accepted as the general precipitating factor, long surgical procedures, the surgical site, and pain can also lead to postoperative urinary retention (1-5).

Urinary retention is seen most often after anterior abdominal wall and anorectal area operations. A cesarean section is an anterior abdominal wall operation. A urinary catheter may be inserted after abdominoperineal operations if there is a likelihood that urinary bladder functions will be impaired due to operation trauma in the sacral plexus. In our country urinary catheters are routinely inserted in patients before they undergo cesarean delivery, and they are removed shortly after surgery.

The literature has reported various methods to encourage voiding after surgery. These have included voiding in a sit- ting position; early ambulation; providing a bedpan; listening to the sound of water; pouring warm water onto the pelvic area; applying pressure on the urinary bladder in the form of a hand massage; pelvic floor exercises (the kegel exercise); and providing diuretic drinks such as tea and coffee. All of these have been reported as treatments for urinary retention in patients who were unable to urinate after urinary catheter removal $(2,4)$. Despite the risk of infection, catheterization has also been recommended when micturition has not been achieved after all noninvasive methods have been tried $(6,7)$.

As mentioned earlier, acute urinary retention is an inability to empty the bladder despite being full, and this complication frequently occurs during the postoperative period. Nurses are able to evaluate the presence of urinary retention, monitor the volume and excessive relaxation of the bladder and avoid unnecessary catheterizations (2-4). The association between urinary catheterization and urinary tract infection is well documented in the literature (5-7).

Genitourinary infection is one of the most common complications (1.7 per 1000) of cesarean deliveries (6). One of the preoperative preparations for cesarean section is the placement of a foley catheter. However, bladder catheterization 
increases the rate of both symptomatic and asymptomatic urinary tract infections. Catheterization of the urinary tract with the use of an indwelling urinary catheter has been implicated as a main cause of urinary tract contamination (5-7).

In one study, urinary system infection was reported in $2-16 \%$ of patients after cesarean section. The variation in rate of occurence depended upon the duration of urinary catheter insertion intra-and postoperatively and on the postoperative health of the mother (1). The prevalence of urinary system infections during the hospital stay was found to be $1.7 \%$, and $65 \%$ of these developed secondary to urinary bladder catheterization. Since experience has now shown that routine urinary catheterization is not necessary for all caesareans, and its use carries a high risk for infection, other approaches need to be explored. The best way to prevent urinary infection is to use urinary catheters as little as possible, and if they are used, they should be removed as soon as possible (5-8).

Massage therapy (therapeutic massage) is the manual manipulation of soft body tissues to enhance health and wellbeing. Massage therapy is one of the oldest forms of medicine known to mankind, having been practiced worldwide since ancient times. In the USA, therapeutic massage was routinely used by physicians, nurses and physical therapists during the late 1800s and early 1900s (9). In nursing practice, in particular, massage therapy is widely used as a complementary therapy providing many benefits. Because it employs the use of touch, and is therefore a direct form of nonverbal communication, massage is a technique that provides both physical and mental relaxation. It also encourages communication between the patient and the nurse (10-13).

Sacral nerve stimulation and massage have been indicated as effective treatment options in recent years for pelvic pain, urinary and fecal incontinence, and functional emptying problems in micturition and defecation. The sacral nerves stimulate the pelvic roof, urinary bladder, the urinary tractus and anal sphincters, and the colon and rectum. Muscles and organs in this area provide urinary and defecation control $(9,14)$. In our study, the effect of regular massage to the sacral region as a noninvasive method for both the prevention of post-cesarean urinary retention and elimination of catheter-related urinary infection risk was evaluated. However, no studies were found in the literature on nursing interventions using massage to the sacral region with the aim of providing postoperative voiding.

\section{Material and Methods}

This interventional study was conducted in Northern Cyprus between 25 February and 27 October 2010. Sampling size was not calculated in the study, as the number of cases in the hospital where it was conducted were too few. There was no similar study previously and it was an interventional study. A random sample of 60 women (20 in intervention Group 1, 20 in intervention Group 2, and 20 in the Control group) who met the selection criteria was included in the study.

Inclusion criteria of the study were as follows: patients who had undergone cesarean delivery, who did not have urinary or neurological problems, who were able to verbally communicate, who had volunteered to participate in this study, who had not had urinary catheters inserted, and who had not experienced contraindications for massage were included in the study.

The first intervention group consisted of women who were given effleurage and friction massages for 10-15 $\mathrm{min}$ by the researcher each hour after completion of the cesarean section. The second intervention group consisted of women who were given effleurage and friction massages after cesarean section for 10-15 min every 30 min after they reported having a voiding sensation. Routine clinical services (having women listen to the sound of water, providing a bedpan, emptying the urinary bladder with a urinary catheter when needed) were provided for the control group in cases of difficulty in voiding.

The data collection form was developed by the researcher by screening the literature and included sociodemographic features of the patients and evaluated variables concerning micturition difficulties after cesarean delivery $(1,2,6,9)$. The results of massage to the sacral region were used for data collection. The data were collected in two stages, with the intervention group first and the control groups thereafter. Within 3.5 months we were able to gather 20 cases for the 1 st intervention group. Knowing that the study process would be prolonged, 20 cases was considered an adequate number for statistical analysis. The other groups also included 20 cases each. Using the NCSS 2007 program, a statistical force analysis of the study was made. Accordingly, voiding time was used as the important parameter for the present study, when $\alpha$ value is taken as $=0.05$ and $\beta=0.05$, statistical power of the study was found to be $99 \%$.

The Statistical Package for the Social Sciences (SPSS) for Windows 15.0 program was used for data analysis. Analysis was performed using Percentage, Mean, Pearson's chi-square test, and One-way analysis of variance (one-way ANOVA).

\section{Ethical considerations}

The Institutional Review Board of Near East University approved the study. Written consent was obtained from the hospital director and verbal consent was obtained from the women prior to the study.

\section{Results}

The women in the three groups had similar demographic characteristics. Statistically significant differences were not present in terms of age, educational status, number of pregnancies, number of deliveries, number of curettages, number of cesareans, indications for cesarean or type of anesthesia $(p \leq 0.05)$ (Table 1). This is important for matching variables between groups (Table 2).

Of the women in the first intervention group, $15 \%$ needed to void 2 hours after cesarean delivery, 35\% needed to void 3 hours after cesarean delivery and $45 \%$ needed to void 4 hours after cesarean delivery; the mean time was $3.4 \pm 0.8$ hours after delivery. Forty percent (40\%) of the women in the second intervention group needed to void 5-6 hours after cesarean delivery and voided within a mean of $5.5 \pm 0.8$ hours. Sixty percent $(60 \%)$ of the women in the control group needed to void after 6 hours and $25 \%$ after seven hours, and the mean time to void was 6.2 20.7 hours (Table 3 ). 
Table 1. Patient characteristics

\begin{tabular}{|c|c|c|c|c|c|c|c|}
\hline \multirow[t]{2}{*}{ Features } & \multicolumn{2}{|c|}{$\begin{array}{l}\text { Intervention } \\
\text { group } 1(n=20)\end{array}$} & \multicolumn{2}{|c|}{$\begin{array}{l}\text { Intervention } \\
\text { group } 2(n=20)\end{array}$} & \multicolumn{2}{|c|}{$\begin{array}{l}\text { Control group } \\
\qquad(n=20)\end{array}$} & \multirow[t]{2}{*}{$\begin{array}{c}\text { Significance } \\
\text { test }\end{array}$} \\
\hline & s & $\%$ & S & $\%$ & $\mathbf{S}$ & $\%$ & \\
\hline \multicolumn{8}{|l|}{ Age (years) } \\
\hline $21-25$ years & 5 & 25.0 & 2 & 10.0 & 4 & 20.0 & \\
\hline $26-30$ years & 7 & 35.0 & 9 & 45.0 & 7 & 35.0 & \\
\hline $31-35$ years & 6 & 30.0 & 3 & 15.0 & 4 & 20.0 & \\
\hline 36 years and above & 2 & 10.0 & 6 & 30.0 & 5 & 25.0 & \\
\hline Mean age $(m e a n \pm s d)$ years & & $29.7 \pm 5.8$ & & $31.8 \pm 5.8$ & & $30.9 \pm 6.1$ & $p=0.668^{\star}$ \\
\hline \multicolumn{8}{|l|}{ Educational status } \\
\hline Less than high school & 4 & 20.0 & 6 & 30.0 & 7 & 35.0 & $\chi^{2}: 3.188$ \\
\hline High school & 6 & 30.0 & 8 & 40.0 & 7 & 35.0 & $p=0.527$ \\
\hline University & 10 & 50.0 & 6 & 30.0 & 6 & 30.0 & \\
\hline \multicolumn{8}{|l|}{ Number of pregnancies } \\
\hline 1 & 9 & 45.0 & 6 & 30.0 & 9 & 45.0 & $\chi^{2}: 4.001$ \\
\hline 2 & 8 & 40.0 & 7 & 35.0 & 4 & 20.0 & $p=0.406$ \\
\hline 3 and more & 3 & 15.0 & 7 & 35.0 & 7 & 35.0 & \\
\hline \multicolumn{8}{|l|}{ Number of deliveries } \\
\hline 1 & 16 & 80.0 & 12 & 60.0 & 12 & 60.0 & $\chi^{2}: 3.050$ \\
\hline 2 & 3 & 15.0 & 5 & 25.0 & 4 & 20.0 & $p=0.514$ \\
\hline 3 & 1 & 5.0 & 3 & 15.0 & 4 & 20.0 & \\
\hline \multicolumn{8}{|l|}{ Number of curettages } \\
\hline 0 & 14 & 70.0 & 15 & 75.0 & 14 & 70.0 & $\chi^{2}: 1.500$ \\
\hline 1 & 4 & 20.0 & 2 & 10.0 & 5 & 25.0 & $p=0.827$ \\
\hline 2 & 2 & 10.0 & 3 & 15.0 & 1 & 5.0 & \\
\hline \multicolumn{8}{|l|}{ Number of cesareans } \\
\hline 1 & 18 & 90.0 & 17 & 85.0 & 14 & 70.0 & $\chi^{2}: 2.894$ \\
\hline 2 and more ${ }^{\star \star}$ & 2 & 10.0 & 3 & 15.0 & 6 & 30.0 & $p=0.235$ \\
\hline \multicolumn{8}{|l|}{ Indications for cesarean } \\
\hline Patient desire & 5 & 25.0 & 5 & 25.0 & 5 & 25.0 & $\chi^{2}: 0.000$ \\
\hline 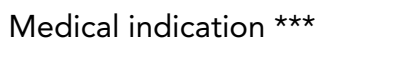 & 15 & 75.0 & 15 & 75.0 & 1 & 5.0 & $p=1.000$ \\
\hline \multicolumn{8}{|l|}{ Type of anesthesia } \\
\hline Spinal & 16 & 80.0 & 15 & 75.0 & 14 & 70.0 & $\chi^{2}: 0.533$ \\
\hline General & 4 & 20.0 & 5 & 25.0 & 6 & 30.0 & $p=0.766$ \\
\hline \multicolumn{8}{|c|}{ 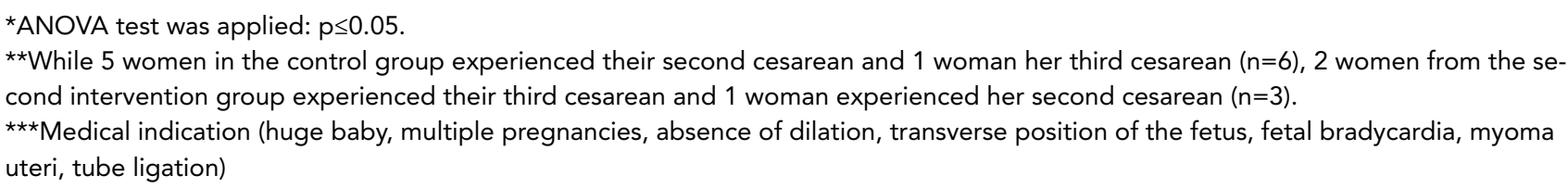 } \\
\hline
\end{tabular}


Of the women in the first intervention group, 95\% needed to void in the first 4 hours after cesarean delivery. The results of the statistical analysis showed a significant difference between all three groups $(p<0.05)$ (Table 4).

Study participants who had spinal anesthesia for cesarean delivery (16 women in the first intervention group, 7 in the second intervention group, and 1 woman in the control group) needed to void within 5 hours or earlier, and the difference between the groups was significant $(p<0.05)$. General anesthesia for cesarean delivery was administered to all 4 women in the first intervention group, 3 women from the second intervention group, and 1 woman in the control group, and they needed to void within 5 hours and earlier. Study results indicated a significant difference between the groups $(p<0.05)$ (Table 5).

Urinary retention did not develop in any of the women in the first intervention group (20 women), while it developed in $5.0 \%$ of the women in the second intervention group ( 1 woman) and in 15\% of the women in the control group ( 3 women). Regarding intervention for retention, a urinary catheter was inserted in three women in the control group, five women had to listen to the sound of water and 12 ambulated. In the second intervention group, a urinary catheter was inserted into one woman who had developed retention. In the statistical analysis, although a significant difference was not found in terms of urinary retention development, the fact that urinary retention did not develop in any of the women in the first intervention group is a very significant finding.

In our study, all women in the first and the second intervention groups who were massaged stated that they felt comfortable after the massage and that they were satisfied with it.

\section{Discussion}

Massage is the most frequently used complementary treatment in nursing practice. Some studies have indicated that massage can help relieve insomnia, headaches, migraines, and dorsalgia. It has also been shown to reduce strain and relieve muscle cramps and offers many other positive effects. All of these form part of the therapeutic role of a nurse and are commonly applied (10-12). In our study, in order to prevent urinary retention, regular massage was applied to the sacral region after cesarean delivery. This was done to replace urinary catheter insertion, which is routinely used for cesarean sections. The effects of the massage were then assessed. A search of the literature could locate no other study investigating this issue. In view of the positive results obtained in our study, which included an improvement in patient satisfaction due to the avoidance of invasive methods, we believe that massage could eliminate the risk of urinary infection as well as that of urinary retention. Furthermore, massage could also reduce hospital costs.

Urinary retention is a common and frustrating complication in women during the immediate postpartum period. Physiological changes in the bladder that occur during pregnancy predispose patients to developing the symptomatic retention of urine during the first few hours to days after delivery $(2-4,15,16)$.

Factors associated with postpartum urinary retention include first vaginal delivery, epidural anesthesia, and cesarean section. Treatment begins with supportive measures to enhance the likelihood of micturition, such as ambulation, privacy, and a warm bath. Nurses or midwives use measures such as oral analgesia, a hot bath, and ambulation for patients who cannot void after 6 hours following cesarean delivery. If these

Table 2. Distribution of post-cesarean voiding times and mean times to voiding $(n=60)$

\begin{tabular}{|c|c|c|c|c|c|c|}
\hline \multirow[t]{2}{*}{$\begin{array}{l}\text { Post-cesarean } \\
\text { voiding time }\end{array}$} & \multicolumn{2}{|c|}{$\begin{array}{l}\text { Intervention } \\
\text { group } 1(n=20)\end{array}$} & \multicolumn{2}{|c|}{$\begin{array}{l}\text { Intervention } \\
\text { group } 2(n=20)\end{array}$} & \multicolumn{2}{|c|}{$\begin{array}{c}\text { Control } \\
\text { group }(n=20)\end{array}$} \\
\hline & $\mathbf{S}$ & $\%$ & $\mathbf{S}$ & $\%$ & $\mathbf{s}$ & $\%$ \\
\hline 2 hours later & 3 & 15.0 & - & - & - & - \\
\hline 3 hours later & 7 & 35.0 & - & - & - & - \\
\hline 4 hours later & 9 & 45.0 & 2 & 10.0 & - & - \\
\hline 5 hours later & 1 & 5.0 & 8 & 40.0 & 2 & 10.0 \\
\hline 6 hours later & - & - & 8 & 40.0 & 12 & 60.0 \\
\hline 7 hours later & - & - & 2 & 10.0 & 5 & 25.0 \\
\hline 8 hours later & - & - & - & - & 1 & 5.5 \\
\hline Mean post-cesarean voiding time & \multicolumn{2}{|c|}{$3.4 \pm 0.8$} & \multicolumn{2}{|c|}{$5.5 \pm 0.8$} & \multicolumn{2}{|c|}{$6.2 \pm 0.7$} \\
\hline
\end{tabular}

Table 3. Distribution of post-cesarean voiding times between control and intervention groups $(n=60)$

\begin{tabular}{|c|c|c|c|c|c|c|c|}
\hline \multirow[t]{2}{*}{$\begin{array}{l}\text { Post-cesarean } \\
\text { voiding time }\end{array}$} & \multicolumn{2}{|c|}{$\begin{array}{l}\text { Intervention } \\
\text { group } 1(n=20)\end{array}$} & \multicolumn{2}{|c|}{$\begin{array}{l}\text { Intervention } \\
\text { group } 2(n=20)\end{array}$} & \multicolumn{2}{|c|}{$\begin{array}{c}\text { Control } \\
\text { group }(n=20)\end{array}$} & \multirow[t]{2}{*}{$\begin{array}{c}\text { Significance } \\
\text { test }\end{array}$} \\
\hline & $S$ & $\%$ & S & $\%$ & S & $\%$ & \\
\hline 4 hours and earlier & 19 & 95.0 & 2 & 10.0 & - & - & $\chi^{2}: 47.912$ \\
\hline 5 hours and later & 1 & 5.0 & 18 & 90.0 & 20 & 100.0 & $p=0.000$ \\
\hline
\end{tabular}


Table 4. Distribution of time taken to void after delivery in the intervention and control groups according to type of anesthesia $(n=60)$

\begin{tabular}{|c|c|c|c|c|c|c|c|c|}
\hline \multirow[t]{2}{*}{$\begin{array}{l}\text { Anesthesia } \\
\text { type }\end{array}$} & \multirow[t]{2}{*}{$\begin{array}{l}\text { Post-cesarean } \\
\text { voiding time }\end{array}$} & \multicolumn{2}{|c|}{$\begin{array}{l}\text { Intervention } \\
\text { group } 1(n=20)\end{array}$} & \multicolumn{2}{|c|}{$\begin{array}{c}\text { Intervention } \\
\text { group } 2(n=20)\end{array}$} & \multicolumn{2}{|c|}{$\begin{array}{c}\text { Control } \\
\text { group }(n=20)\end{array}$} & \multirow[t]{2}{*}{$\begin{array}{c}\text { Significance } \\
\text { test }\end{array}$} \\
\hline & & $\mathrm{S}$ & $\%$ & $\mathbf{S}$ & $\%$ & S & $\%$ & \\
\hline \multirow[t]{2}{*}{ Spinal anesthesia } & 5 hours and earlier & 16 & 100.0 & 7 & 46.7 & 1 & 7.1 & $\chi^{2}: 26.269$ \\
\hline & 6 hours and later & - & - & 8 & 53.3 & 13 & 92.9 & $p=0.000$ \\
\hline \multirow[t]{2}{*}{ General anesthesia } & 5 hours and earlier & 4 & 100.0 & 3 & 60.0 & 1 & 16.7 & $\chi^{2}: 6.830$ \\
\hline & 6 hours and later & - & - & 2 & 40.0 & 5 & 83.3 & $p=0.014$ \\
\hline
\end{tabular}

Table 5. Distribution of intervention and control groups according to urinary retention development and urinary catheter insertion status

\begin{tabular}{|c|c|c|c|c|c|c|}
\hline \multirow[t]{2}{*}{$\begin{array}{l}\text { Urinary retention } \\
\text { and intervention }\end{array}$} & \multicolumn{2}{|c|}{$\begin{array}{l}\text { Intervention } \\
\text { group } 1(n=20)\end{array}$} & \multicolumn{2}{|c|}{$\begin{array}{l}\text { Intervention } \\
\text { group } 2(n=20)\end{array}$} & \multicolumn{2}{|c|}{$\begin{array}{c}\text { Control } \\
\text { group }(n=20)\end{array}$} \\
\hline & $\mathbf{S}$ & $\%$ & $\mathbf{S}$ & $\%$ & $\mathbf{S}$ & $\%$ \\
\hline \multicolumn{7}{|l|}{ Urinary retention } \\
\hline Developed & - & - & 1 & 5.0 & 3 & 15.0 \\
\hline Did not develop & 20 & 100.0 & 19 & 95.0 & 17 & 85.0 \\
\hline \multicolumn{7}{|l|}{ Intervention for retention } \\
\hline Urinary catheter insertion & - & - & 1 & 100.0 & 3 & 15.0 \\
\hline Having women listen to the sound of water & - & - & - & - & 5 & 25.0 \\
\hline Ambulation & - & - & - & - & 12 & 60.0 \\
\hline
\end{tabular}

measures are not successful, catheterization can be performed $(2-4,16)$. In our study, the nurses encouraged ambulation and listening to the sound of water in women in the control group, and one urinary catheter was inserted into a woman who did not respond to these measures (Table 5). However, all of the women in the intervention groups, who were regularly massaged in the sacral region, were able to void 5 hours or before, and none of them had a catheter inserted. There was a significant difference between the intervention and control groups in terms of mean time to void $(p<0.05)($ Tables 2,3$)$, and this result is striking in terms of indicating that urinary retention may be prevented with massage to sacral region instead of having to use urinary catheter insertion.

Urinary catheters can lead to trauma and increase the risks of infection and bladder dysfunction. Approximately $25 \%$ of urinary catheterizations are not clinically necessary (8). Ghoreishi's study determined that the routine use of an indwelling urinary catheter in cesarean section patients with a stable hemodynamic condition is not necessary (6). While urinary catheter insertion is routinely performed after cesarean delivery in the hospital where this study was conducted, during our study, only the patients of the doctor involved in this study did not have urinary catheters inserted. In other hospitals in the country, urinary catheter insertion is routinely performed after cesarean delivery, which limited the number of our cases. Another factor limiting the number of participants was that the location of our study in the North Cyprus Turkish Republic is part of an island with a population of just 294,906 , hence few cases were available. In the hospital where the study was conducted, 6-10 cesarean operations are carried out monthly (17).

According to our observations, although epidural anesthesia is preferred in cesarean operations in most hospitals, spinal anesthesia was used for most of the patients in the present study whereas general anesthesia was only used in a small group. This difference may have been related to the knowledge and professional expertise of the anesthetist working in the hospital. In our study, while spinal anesthesia was given to $80 \%$ of the first intervention group, $75 \%$ of the second intervention group and to $70 \%$ of the control group, the others were administered general anesthesia (Table 1). All of the women (four women) who were given general anesthesia in the first intervention group were able to urinate within the first 5 hours following their cesarean procedure.

Most of the women in the control group given spinal or general anesthesia were able to urinate after 6 hours or longer following cesarean delivery (Table 4). These results indicate that massage has a facilitating effect on cesareans performed using spinal anesthesia. Epidural analgesia with morphine was significantly associated with post-cesarean urinary retention $(18,19)$.

Massage might stimulate parasympathetic activity. Voiding dysfunctions, which include incontinence, retention, and chronic pelvic pain, are relatively frequent problems that can be difficult to manage. Neuromodulation via stimulation of the sacral nerves has been shown to improve these symptoms, although the exact mechanisms remain elusive. Stimulation has a role in assisting bladder emptying as well $(9,14,20)$. 
Ghoreishi (6) also reported the satisfaction of women who did not have a urinary catheter inserted after cesarean delivery as an important finding. Likewise, in the present study, all of the women who were given a massage stated that they were satisfied with this technique. According to these results, we can conclude that massage to the sacral region shortened the time to void, protected the women from a risk of urinary infection as no urinary catheters were inserted, and improved patient satisfaction as the women were not subjected to invasive procedures. Additionally, this method may contribute to reduced hospital costs as urinary catheters will not be used.

According to the results of this study, massaging the sacral region for 10-15 minutes in patients who were having difficulties with urinating was effective at preventing urinary retention after cesarean delivery. Furthermore, the patients were able to urinate more easily and within a shorter time after delivery, making them feel more relaxed and satisfied. Massaging postoperative patients immediately may reduce urinary retention and unnecessary catheterizations and therefore reduce the risk of urinary tract infection associated with catheterization. Given these results, it is recommended that massage to the sacral region should be practically taught to nurses and offered to patients who experience this problem. It is our recommendation that massaging the sacral region instead of urinary catheter insertion should be studied in larger groups and after short abdominal surgery procedures.

Ethics Committee Approval: Ethics committee approval was received from the The Institutional Review Board of Near East University for this study.

Informed Consent: Written consent was obtained from the hospital director and verbal consent was obtained from the women prior to the study.

Peer-review: Externally peer-reviewed.

Author contributions: Concept - Ü.D., A.E.K., K.E., B.K., A.Y.; Design - Ü.D., A.E.K., K.E., B.K., A.Y.; Supervision - K.E.; Resource - A.Y.; Materials - Ü.D., A.E.K., K.E., B.K., A.Y.; Data Collection\&/or Processing - A.E.K.; Analysis\&/or Interpretation - B.K.; Literature Search - Ü.D., A.E.K., K.E., B.K., A.Y.; Writing - Ü.D.; Critical Reviews - Ü.D., A.E.K., K.E., B.K., A.Y.

Conflict of Interest: No conflict of interest was declared by the authors.

Financial Disclosure: No financial disclosure was declared by the authors.

\section{References}

1. Özgünen FT, Evrüke C. Maternal fetal tıp ve perinatoloji. Medical Network Ankara:2001;1322-30.

2. Glavind K, Bjork J. Incidence and treatment of urinary retention postpartum. Int Urogynecal J 2003;14:119-21. [CrossRef]

3. Shing-Kai Y, Daljit S, Man-Wah P, Allan C. Postpartum urinary retention. Acta Obstet Gynecol Scand 2004;83:881-91. [CrossRef]

4. Humburg J. Postartum urinary retention without clinical impact? Ther Umsch 2008;65:681-5. [CrossRef]

5. Palese A, Buchini S, Deroma L, Barbone F. The effectiveness of the ultrasound bladder scanner in reducing urinary tract infections:a meta-analysis. J Clin Nurs 2010;19:2970-9. [CrossRef]

6. Ghoreishi J. Indwelling urinary catheters in cesarean delivery. Int J Gynaecol Obstet 2003;83:267-70. [CrossRef]

7. Tambyah PA. Catheter-associated urinary tract infections:diagnosis and prophylaxis. Int J Antimicrob Agents 2004;24:44-8. [CrossRef]

8. Nazarko L. Effective evidence-based catheter management:an update. Br J Nurs 2010;19:948-53.

9. Dixon MW. Massage therapy, complementary therapies in Neurology. In:An Evidence-Based Approach Edited by Barry S. Oken. The Parthenon Publishing Group, London:2004;113-15.

10. Pfeil M. Role of nurses in promoting complementary therapies. Br J Nurs 1994;3:217-9.

11. Tracy MF, Lindguist R. Nursing's role in complementary and alternative therapy use in critical care. Crit Care Nurs Clin North Am 2003;15:289-94. [CrossRef]

12. Khorshid L, Yapucu Ü. The nurse's role in complementary therapies. Atatürk Üniversitesi HYO Derg 2005;8:124-30.

13. Çoban A, Şirin A. Effect of massage for five days on degree of edema, pain, fatigue and sleeplessness in pregnant with physiologic edema in lower limbs. Genel Tıp Derg 2009;19:51-6.

14. Mayer RD, Howard FM. Sacral nerve stimulation, neuromodulation for voiding dysfunction and pain. Neurotherapeutics 2008;5:107-13. [CrossRef]

15. Darrah DM, Griebling T, Silverstein JH. Postoperative urinary retention. Anesthesiol Clin 2009;27:465-84. [CrossRef]

16. Liang CC, Chang SD, Chang YL, Chen SH, Chueh HY, Cheng PJ. Postpartum urinary retention after cesarean delivery. Int J Gynaecol Obstet 2007;99:229-32. [CrossRef]

17. KKTC 2011 general house and population census results. Available from www.devplan.org/2011\%20 population census results . 05 August 2012.

18. Groutz A, Gordon D, Wolman I, Jaffa A, Kupferminc MJ, Lessing JB. Persistent postpartum urinary retention in contemporary obstetric practice. J Reprod Med 2001;46:44-8.

19. Liang CC, Chang SD, Wong SY, Chang YL, Cheng PJ. Effects of postoperative analgesia on postpartum urinary retention in women undergoing cesarean delivery. J Obstet Gynaecol Res 2010;36:991-5. [CrossRef]

20. Lamas K, Lindholm L, Hans S, Stenlund H, Engström B, Jacobsson C. Effects of abdominal massage in management of constipation-A randomized controlled trial. Int J Nurs Stud 2009:46:759-67. [CrossRef] 